\title{
Simulation of Droplet Combustion for Monopropellants
}

\author{
Nikhil Jain ${ }^{1}$, Mahavir Choudhary² \\ ${ }^{1,2}$ JECRC University, Ramchandrapura, Vidhani Village, Jaipur, Rajasthan, India
}

\begin{abstract}
This paper revisits the literature pertinent to droplet combustion studies for liquid monopropellants as well as practical applications of monopropellants in internal combustion engines. A review is presented on the scope and different applications of the concept of droplet combustion in various applications, such as diesel engines, rocket engines, gas turbines, oil fired boilers, and furnaces etc. Our major objective is the numerical analysis of monopropellants droplet combustion. Combustion of a single monopropellant droplet in an oxidizing and a non-oxidizing atmosphere was studied in order to understand the basic mechanism by which combustion occurs in such systems. In this study a semi empirical model for hybrid combustion of hydrazine was implemented in order to extract the mass burning rate for hybrid combustion. Additionally, the temperatures and diameters of various flames were determined. The detailed theoretical studies characterizing the combustion of monopropellant blends in the form of droplets have been reported. At different droplet diameter and ambient oxygen mass fraction, both experimental and predicted mass burning rate were found to be similar. Also flame diameter and temperature were found to be of increasing nature with increase in droplet diameter and oxygen mass fraction.
\end{abstract}

Keywords: Monopropellant, Combustion, Droplet, Hydrazine

\section{Introduction}

Propellants are a chemical substance used to produce energy or pressurized gases which are subsequently used to generate propulsion of vehicle, or other object. Propellant can be categorized as monopropellant and bipropellant. Bipropellant system consist combustion of fuel and oxidizer while monopropellant system consist combustion of single fuel. Monopropellants are propellant/chemical that releases energy through exothermic decomposition reaction. The molecular bond energy of monopropellant usually release through use of catalyst to produce large volume of energetic gases. Bipropellants releases energy through the chemical reaction between an oxidizer and a fuel [1]. Monopropellants have been utilized in propulsion systems required to operate in oxygen deficient scenarios such as robotic actuators, underwater power sources, and high altitude unmanned aerial vehicles. Hydrazine and its derivatives such as monomethyl hydrazine $(\mathrm{MMH})$, and unsymmetrical dimethyl hydrazine (UDMH) are the most widely used monopropellants. Droplet combustion is one of the key steps in the complicated structure of multiphase spray combustion. Hence, the initial characterization of monopropellant combustion can be carried out by droplet combustion. Prerequisite to the understanding of droplet combustion is the understanding of the combustion process for an individual drop [2].

\section{Literature Survey}

Main objective of present study is prediction of combustion characteristics of hydrazine fuel using a mathematical model of hybrid combustion. Combustion process consists of flame surrounding the droplet. During droplet combustion, fuel vapour from the liquid surface diffuses radially outwards. The oxidizer from atmosphere diffuses radially inward toward the droplet surface [3]. Fuel and oxidizer react fully, consuming one another in the flame zone as they diffuse towards each other. The flame is typically represented as an infinitesimally thin sheet. Heat generated by the reaction is conducted inwards from the flame zone to provide the energy for vaporizing the fuel at the liquid surface. The droplet surface is assumed to be at the boiling point of the liquid. In Fig 1 droplet combustion under the microgravity conditions is considered. Fuel at the droplet surface vaporizes after absorbing the heat.

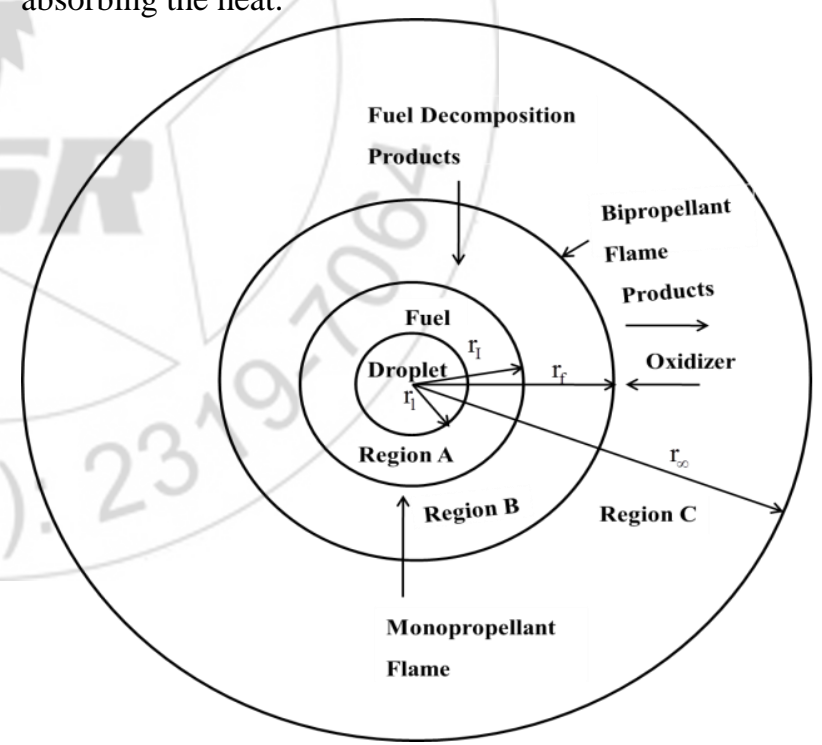

Figure 1: Various zones considered for the hybrid combustion model [4].

The fuel vapor emanating from the droplet diffuses radially outwards through region $\mathrm{A}$, and undergoes a decomposition reaction forming the monopropellant flame at a distance of $r_{I}$. The products of the decomposition reaction diffuse out towards the oxidizing atmosphere where they are further oxidized in the bipropellant flame [4]. 


\section{International Journal of Science and Research (IJSR) \\ ISSN (Online): 2319-7064}

Index Copernicus Value (2013): 6.14 | Impact Factor (2015): 6.391

\section{Methodology}

The solution methodology is dependent on the type of equations and number of unknowns. Here both implicit and explicit types of equations are presented. The implicit type equations were solved by using a generalized Newton Raphson method. The Newton -Raphson method can be used for system of nonlinear equations [5].

$$
x_{k+1}=x_{k}-\frac{f\left(x_{k}\right)}{f^{\prime}\left(x_{k}\right)}=x_{k}-\frac{f\left(x_{k}\right)}{\frac{d f}{d x}\left(x_{k}\right)}
$$

For simulation work "MATLAB (Matrix Laboratory )", was used. MATLAB is a multi paradigm numerical computing environment and programming language. It allows matrix manipulations, plotting of functions and data, implementation of algorithms. For plotting the graph "'OriginPro 8", was used. This software uses different value for $\mathrm{x}$-axis and $\mathrm{y}$-axis with no. of result presented in one single plot [6].

\section{Numerical Analysis}

Simulation was done for varying droplet diameter ranging from 0.13 to $1.91 \mathrm{~cm}$ and for different amount of oxygen mass fraction varying from 0.043 to 0.418 . The value of activation energy and pre exponential factor for hydrazine is given in the table below. Also given in the table below are properties of hydrazine used in theoretical model.

Table 1: Value of Activation Energy and Corresponding PreExponential Factor [5]

\begin{tabular}{|c|c|}
\hline ctivation Energy $(E)$ & Pre-Exponential Factor $(A)$ \\
\hline 0 & 0.0136 \\
\hline 10 & 0.1040 \\
\hline 30 & 6.106 \\
\hline
\end{tabular}

\section{Result}

The analytical model was used to determine the values of the mass burning rates, flame diameters, and flame temperatures for the hybrid combustion case. Since several initial guesses led to accurate values of the above-mentioned parameters, the guesses that generated the minimum error between the experimental and predicted mass burning rates were chosen, and the corresponding values of the other parameters were plotted against the independent variables.

Figures show mass burning rate of hydrazine at varying droplet diameter and varying oxygen mass fraction.

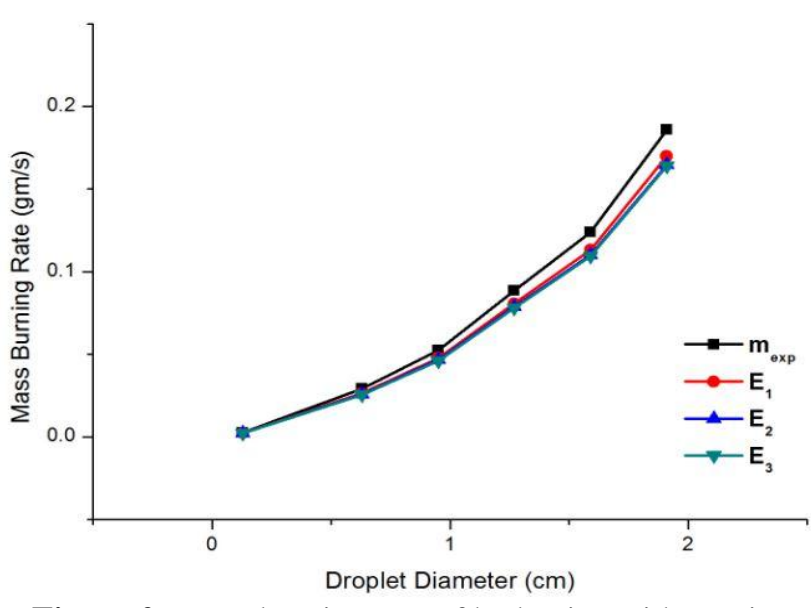

Figure 2: Mass burning rate of hydrazine with varying droplet diameters

Figure 1 displays the variation of the experimental and predicted mass burning rates for hydrazine with droplet diameter in an oxidizing atmosphere. The predicted mass burning rates were found to be similar to the experimental mass burning rates for all three pairs of activation energies and pre exponential factors, also simulation shows that better predictions were obtained with $\mathrm{E}_{1}$

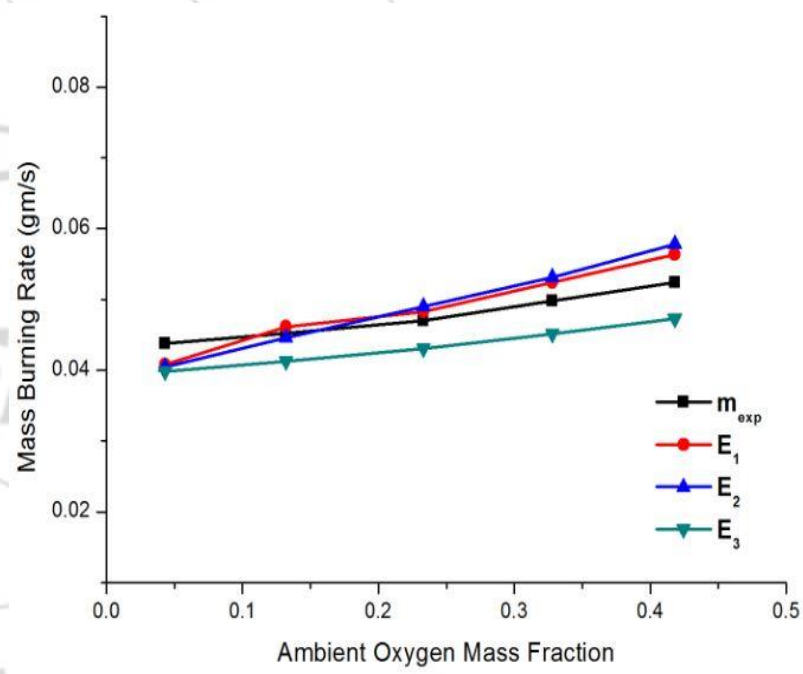

Figure 3: Mass burning rate of hydrazine with varying ambient oxygen mass fraction

The variations of various parameters with ambient oxygen mass fraction from 0.043 to 0.418 were plotted in Figure 2 . The droplet size was kept constant at $0.95 \mathrm{~cm}$ for these experiments. The hybrid mass burning rates of hydrazine exhibited an increasing trend with the oxygen mass fractions, and was found to be predicted appropriately for all the pairs of activation energies and pre exponential factors. 


\section{International Journal of Science and Research (IJSR) \\ ISSN (Online): 2319-7064}

Index Copernicus Value (2013): 6.14 $\mid$ Impact Factor (2015): 6.391

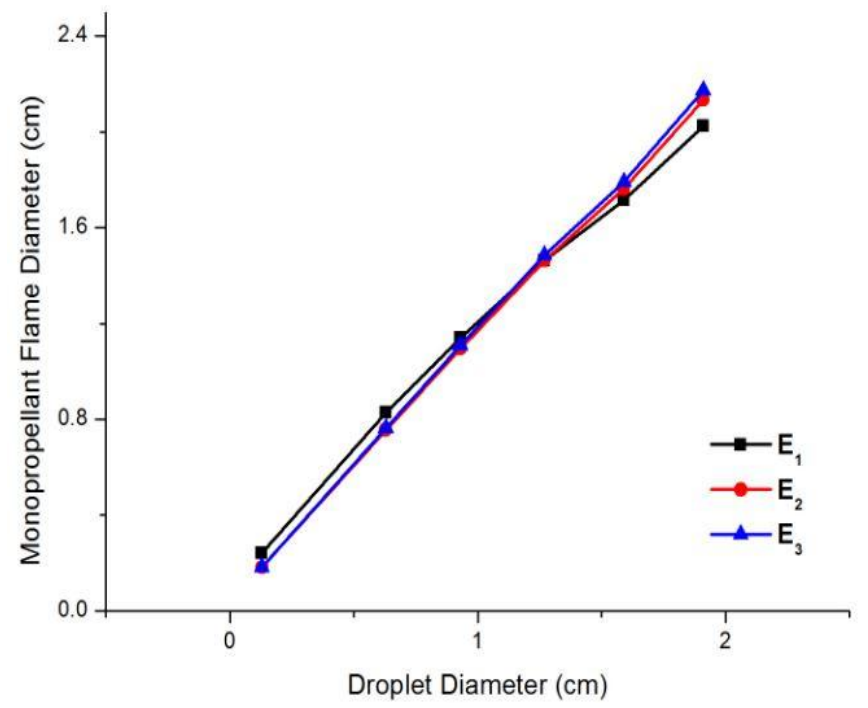

Figure 4: Variation of monopropellant flame diameter with varying drop diameter

Mass burning rates for the hybrid combustion case vary more acutely with the droplet diameter, thus demonstrating the effect of the monopropellant flame. The non-linear variation of the mass burning rates for hybrid combustion may be explained by considering the energy balance at the droplet surface, the monopropellant flame and the bipropellant flame. It is evident from the increasing that the effect of the monopropellant flame increases with droplet diameters

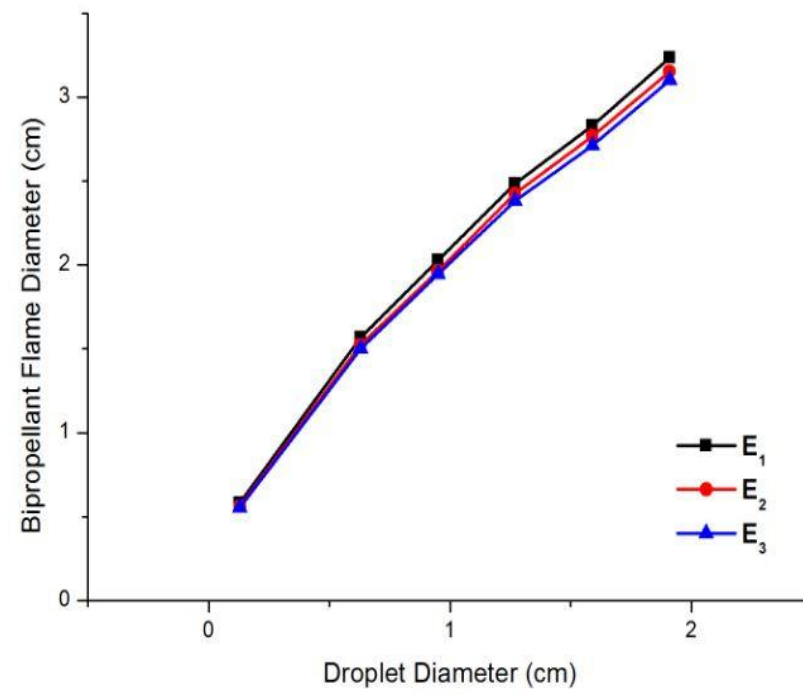

Figure 5: Variation of Bipropellant flame diameter with varying drop diameter

Since the mass burning rates are dependent on the energy conducted from the monopropellant flame to the droplet surface, hence the monopropellant flame temperatures should increase rapidly to supply the additional energy required. Since the energy conducted from the monopropellant flame is balanced by the sum of the energy conducted from the bipropellant flame and the constant heat of decomposition of hydrazine, the energy conducted from the bipropellant flame has to increase as well.

\section{Conclusion}

Simulation was done for two different cases. One for varying droplet diameter whiles other at different oxygen mass fraction. In both case monopropellant and bipropellant flame diameter found to be increase with varying droplet diameter while in case of varying oxygen, droplet was kept constant, and hence both monopropellant and bipropellant diameter were found to be constant. Increasing the droplet diameter and ambient oxygen mass fraction was found to increase the mass burning rate.

In case of varying droplet diameter simulation result varies from experimental result as $9 \%, 12 \%$ and $13 \%$ for all three pair of activation energy respectively while in case of varying oxygen, percentage variation was $7 \%, 8 \%$ and $10 \%$.

\section{References}

[1] Allison C.B., Faeth G.M., "Decomposition and hybrid combustion of hydrazine", $\mathrm{MMH}$ and UDMH as droplets in a combustion gas environment. 213-226 (1977)

[2] Turns S.R., 'An Introduction to Combustion', 111-148 (2000), Second Edition, McGraw Hill Publication.

[3] Ambekar A, Chowdhury A. "Combustion of Blended Monopropellants", 42-48, (2012), 48th AIAA/ASME/SAE/ASEE Joint Propulsion Conference and Exhibition, Atlanta, Georgia

[4] Kuo K.K., 'Principle of Combustion', $41-57$ (2005), Second Edition, John Wiley \& Sons.

[5] Rosser W.A., Peskin RL. "A Study of Decomposition Burning”, 152-160 (1996), Vol. 10, Combustion and Flame.

[6] Williams F. A., 'Theory of Burning of Monopropellant Droplets', 17-24, March (1993), Vol. 7, Combustion and Flame.

\section{Author Profile}

Nikhil Jain received the B.Tech Degree in Mechanical Engineering from Stani Memorial College of Engineering and Technology, Jaipur, Rajasthan in 2013 and M.Tech Degree in Thermal Engineering from JECRC University, Jaipur, Rajasthan in 2015. Currently, He is an Assistant Professor of Mechanical Engineering at JECRC UDML College of Engineering. His teaching and research area includes Thermal Engineering and Fuel Combustion. 